\title{
¿La educación artística y estética contribuye al desarrollo de la inteligencia emocional? Un caso.
}

\section{Does artistic and aesthetic education contribute to the development of the emotional intelliqence? A fact.}

\author{
María José López Morillas \\ Escuela Infantil Santa Catalina (Jaén) \\ mjlm0011@gmail.com
}

Recibido 03/04/2018 Aceptado 08/12/2018
Revisado 16/12/2018 Publicado 14/06/2019

\section{Resumen:}

La presente investigación basada en las artes busca integrar en el aula de Educación Infantil la educación estética y artística, debido a sus múltiples beneficios para la inteligencia emocional del alumnado, y por consiguiente, en el desarrollo del resto de las inteligencias y en las competencias clave de nuestro currículo.

Para llevar a cabo esta investigación, se han realizado en un aula de 25 niños y niñas en una zona rural de Jaén tres propuestas didácticas con un incremento de dificultad en cada una de ellas. La finalidad de la investigación es observar qué indicadores de la inteligencia emocional ponen el alumnado de manifiesto a través de estas actividades artísticas. 
¿La educación artística y estética contribuye al desarrollo de la inteligencia emocional? Un caso.

https://dx.doi.org/10.17561/rtc.n16.4

intelligences and in the key competences of our curriculum.

To carry out this research, three didactic proposals with an increase of difficulty in each of them have been made in a classroom of 25 children in a rural area of Jaén. The purpose of the research is to observe that indicators of emotional intelligence make the student manifest through these artistic activities.
Palabras Clave: Educación Infantil, educación artística, inteligencias múltiples, inteligencia emocional, investigación basada en las artes.

Key words: infantile education, artistic education, miltiple intelligences, emotional intelligence, investigation base don the arts. inteligencia emocional? Un caso. Tercio Creciente, 16, págs. 95-116. https://dx.doi.org/10.17561/rtc.n16.4

LÓPEZ MORILLAS, MARÍA JOSÉ ¿La educación artística y estética contribuye al desarrollo de la inteligencia emocional? Tercio Creciente, julio, 2019. $n^{\circ} 16$, pp. 95-116.

https://dx.doi.org/10.17561/rtc.n16.4 


\section{Introducción}

Esta investigación surge de la necesidad de incluir la educación estética y artística en el aula de infantil, sobre todo, de descubrir si a través de la realización de prácticas artísticas se desarrolla la inteligencia emocional de los niños y niñas y cómo (Cueva Ramírez, 2017: 153).

Siempre se relaciona la inteligencia emocional con las emociones -alegría, orgullo, tristeza, vergüenza, etc. - , pero según Goleman en 2012 hay cuatro pilares de éste tipo de inteligencia. El primer pilar es comprender nuestras emociones, que es el más conocido por todos y que actualmente se suele trabajar en las aulas. El segundo pilar, es la autorregulación, que consiste en partir del primer pilar para utilizar estrategias que nos ayuden a regular nuestros estados de ánimo. Estos dos pilares son más de índole de desarrollo personal (Soto Sánchez, 2017: 12). El tercero es la empatía con los demás, aspecto muy importante para trabajar en el aula de Educación Infantil a la par que difícil por el egoísmo típico de esta edad. Y el último pilar son las habilidades sociales, otro aspecto esencial, ya que una de las finalidades de la educación es contribuir al desarrollo social del alumnado.

Por tanto, esta investigación se basa en los cuatro pilares, ya que además de las emociones hay aspectos como la motivación, la autonomía o valores tan importantes como la responsabilidad, la toma de decisiones, etc. Que han de ser igualmente considerados en este tipo de estudios.
Para ello, se han realizado tres propuestas de actividades artísticas en un aula con niños y niñas de 5 años en una zona rural de Jaén. En cada una de las propuestas se enfrentan a la realización de diferentes productos artísticos en situaciones varias y con diversos materiales. Con estas propuestas deben poner en juego diferentes aspectos de la inteligencia emocional, que normalmente no trabajan en el aula.

La investigación principalmente está basada en las artes y consiste en:

...un método de indagación que utiliza elementos de la experiencia de las artes creativas como maneras de comprender el significado de lo que nosotros hacemos dentro de nuestra práctica y de la enseñanza (Hernández, 2008).

Aunque existen numerosos estudios semejantes al que se propone en este trabajo, como podría ser el realizado por Marquínez y Betancourt (2015), donde proponen distintas propuestas didácticas de autoconocimiento a través de la fotografía para adolescentes con la finalidad de que se expresen y que se llegue a entender qué les ocurre en esa etapa de rebeldía. Sin embargo, el objetivo de esta investigación es observar cómo reaccionan los niños y niñas en las diferentes propuestas artísticas, cómo desarrollan la inteligencia emocional para resolver las distintas situaciones y qué aspectos de la misma se trabajan.

Para iniciar esta investigación comenzaremos por la fundamentación 
¿La educación artística y estética contribuye al desarrollo de la inteligencia emocional? Un caso.

https://dx.doi.org/10.17561/rtc.n16.4

teórica sobre los campos de interés que la abarcan.

\section{A. Educación estética y educación artística}

Teniendo en cuenta estudios realizados por Caíña (2008), Mairal (2011), Sánchez (2010) y Ubals Álvarez (2005), se explica la educación estética y educación artística.

La educación es un proceso de asimilación y aprendizaje de conocimientos y adquisición de habilidades, cultura y valores válidos para nuestra sociedad. Esto se produce proporcionando al alumnado las herramientas necesarias, explotando así todo su potencial.

El arte es un concepto muy amplio que difícilmente podemos definir. Pero, se considera como un conjunto de creaciones humanas con la finalidad de expresar sentimientos, sensaciones e ideas que el artista quiere visibilizar a través de lo visual, de lo sonoro, de lo corporal o lo lingüístico. Pero sobre todo, es una forma de crítica social.

La estética es un concepto más amplio que el arte. Investiga la apariencia exterior de lo que se encuentra en el universo. Se puede decir que es un aspecto expresivo y comunicativo que se estimula dentro y fuera de la educación artística.

Así pues, la educación estética y artística son dos conceptos muy cercanos y a menudo los interpretamos como un todo, pero a continuación vamos a diferenciarlas y, a su vez, descubrir cómo se complementan.

La educación estética es la formación de una actitud sobre todo lo que posea un valor estético en el universo como la naturaleza, los humanos, el arte, etc. En cambio, "la educación artística es una experiencia de aprendizaje donde se educa el sentimiento" (Susanne Langer, 2010) y que forma a las personas en tener una necesidad para tener una actitud e interaccionar con el arte gracias a la actuación de la familia, la escuela y los medios de comunicación.

La educación artística está presente en los colegios de nuestro país a través de la educación plástica, la educación musical y la educación física. Son asignaturas diferenciadas y que tienen como finalidad que el alumnado obtenga los mejores conocimientos y habilidades en estas materias. En cambio, estas asignaturas no tienen una gran relevancia en nuestro currículo escolar.

Por tanto, la educación estética educa en lo estético y la educación artística educa el sentimiento producto de la interacción con el arte. Como decía Dewey (2008), la educación estética y artística enseña a intensificar la vida en vez de conformarse simplemente con vivirla.

\section{B. Inteligencia emocional}

Para comprender qué es la inteligencia emocional, hay que partir de qué es la inteligencia:

... es una capacidad del individuo para dar solución a problemas de su entorno o de crear productos o servicios de utilidad 
y que se desarrollan en función de los estímulos que se reciban, del nivel de desarrollo y del propio trabajo y esfuerzo (Gardner, 1998).

Gardner (2012) defiende que el individuo tiene ocho inteligencias diferentes y que cada una de ellas se encuentra en una zona del cerebro, en función si la inteligencia es más creativa o más lógica, pero que actúan de manera conjunta e indivisible. Actualmente, esta teoría de localización de las inteligencias no es validada por la neurociencia, ya que se aportan otras teorías que también hay que poner en duda.

No obstante, se considera que la teoría de las Inteligencias Múltiples no es una teoría científica sino una herramienta educativa para atender a la diversidad del alumnado, tal y como indica Guillén (2015) en el blog Escuela con cerebro.

Sea como fuere, teoría científica o herramienta educativa, lo más importante es atender a la diversidad del aula y a las características, necesidades e intereses del alumnado y por ello es importante el desarrollo de todas y cada una de las inteligencias múltiples.

Una de estas ocho inteligencias es la emocional, defendida como la habilidad para expresar, generar y entender emociones y sentimientos propios y de los demás (Mayer y Geher, 1966). Además, esta inteligencia, abarca la inteligencia interpersonal e intrapersonal.

La interpersonal es el potencial para interactuar con las emociones, sentimientos y deseos de los demás. La intrapersonal, el potencial para administrar la información relacionada con uno mismo, con las capacidades y dificultades (Escamilla, 2014).

Goleman (2012), en sus diversas investigaciones obtiene como resultado que la inteligencia académica no nos prepara para la vida. Por tanto, es necesario que la escuela ejerza una función más directa en las habilidades emocionales que ayudan a la capacidad de autorregularnos en el comportamiento diario, tenemos dos mentes, una que piensa y otra que siente (Goleman, 1995).

La etapa de Educación Infantil es un período en el que se aprenden las lecciones emocionales más importantes, de ahí a la necesidad de incluir la inteligencia emocional en el aula (Escamilla, 2014).

\section{PROPUESTAS DIDÁCTICAS}

La Educación Infantil es una etapa educativa con entidad propia, que recoge a los alumnos de 0 a 6 años de edad. Específicamente, las propuestas se han puesto en práctica en un aula de 5 años con 25 niños y niñas de un CEIP de una zona rural de Jaén.

Para ello se han programado tres actividades artísticas diferentes, observando de esta forma cómo reaccionan y cómo resuelven la actividad para la elaboración del producto artístico de cada una de ellas.

Estas propuestas tienen una dificultad ascendente, siendo la primera más sencilla y la última la más complicada y donde tendrán que poner en práctica 
aspectos como la autonomía, la toma de decisiones, la autoconfianza, canalizar la frustración, respetar las decisiones tomadas en grupo y desarrollar la creatividad.

La primera actividad realizada fue "Miniyó", que consistió en que los niños y niñas tenían que modelar con plastilinas una figura de ellos mismos. Esta actividad estuvo continuamente dirigida por el docente, ya que se les dio instrucciones de lo que tenían que hacer $y$ con qué material. No obstante la creatividad de la práctica viene dada en el propio proceso de creación, ya que cada alumno/a realizó la figura tal y como ellos se veían a sí mismo.

El material utilizado fue plastilinas de distintos colores - rojo, azul, rosa, carne, marrón, amarillo y verde-, palitos de madera y corchos. La duración de la actividad, fue aproximadamente de unos 45 minutos.

El objetivo principal de esta actividad fue conocerse a ellos mismos modelando rasgos de su personalidad o elementos que los definan. Además, esta práctica les ayudó a desarrollar el autoconocimiento, la psicomotricidad fina, el autoconcepto o expresarse a través de lenguaje oral y el lenguaje artístico.

Para la realización de esta actividad, la organización espacial fue a través de rincones, que es la organización del aula donde se integran actividades de aprendizaje para facilitar la participación activa de los niños y niñas en la construcción de sus propios conocimientos $y$, por tanto, de su aprendizaje (Laguía y Vidal, 2007).

En el caso de estas autoras, defienden los rincones donde las actividades son diferentes en cada uno y los niños y niñas deben de pasar por todos los rincones para realizar todas las actividades, ya sea diariamente o semanalmente. En mi caso, respeté la organización en rincones que tenían, pero todos realizaron la misma actividad a la vez.

\begin{tabular}{|l|l|}
\hline Título actividad & "Miniyó" \\
\hline $\begin{array}{l}\text { Materiales } \\
\text { utilizados }\end{array}$ & $\begin{array}{l}\text { Plastilinas de colores } \\
\text { Palitos de madera } \\
\text { Corcho }\end{array}$ \\
\hline Duración & 45 ' \\
\hline Objetivo & $\begin{array}{l}\text { Conocerse } \\
\text { modelando rasgos } \\
\text { de su personalidad y } \\
\text { elementos que los } \\
\text { definen. }\end{array}$ \\
\hline
\end{tabular}

La segunda actividad propuesta fue "Cuéntame un cuento", que consistió en un taller de creación de relatos. Esta actividad fue dirigida, pero menos que la anterior, ya que se les dijo que íbamos a inventarnos un cuento y se les guio en la fórmula y pautas de creación de cuentos pero la imaginación fue libre en cuanto toda la invención del mismo.

El material que se utilizó fue la creatividad y la imaginación y en algunos momentos unos dados cuentacuentos y una pizarra donde apuntábamos lo que se iba inventando y acordando. La duración aproximada de esta sesión fue de unos 50 minutos. 
El objetivo de la creación del cuento fue tomar decisiones en cuanto a la narrativa del cuento, los personajes o el lugar donde ocurren los hechos, llegar a acuerdos entre las diferentes opciones propuestas y trabajar en grupo. Además, trabajar con textos de la vida cotidiana como es el cuento, desarrollar el lenguaje oral, respetar a los demás y aceptar lo que se acuerde en la mayoría.

En este caso, la organización espacial fue la asamblea, que es un espacio del aula y un momento de la jornada escolar donde se realizan actividades diarias como pasar lista, ver el tiempo que hace - elegir el responsable del día. Pero además de estas actividades se realizan otras del tema del proyecto de trabajo o unidad didáctica que están trabajando. Son un espacio comunicativo, expresivo, flexible y adaptado (D'Angelo y Medina, 1997).

\begin{tabular}{|l|l|}
\hline Título actividad & $\begin{array}{l}\text { "Cuéntame un } \\
\text { cuento" }\end{array}$ \\
\hline $\begin{array}{l}\text { Materiales } \\
\text { utilizados }\end{array}$ & $\begin{array}{l}\text { Dados } \\
\text { cuentacuentos } \\
\text { Pizarra }\end{array}$ \\
\hline Duración & $50^{\prime}$ \\
\hline Objetivo & $\begin{array}{l}\text { Iniciativa en la } \\
\text { toma de decisiones } \\
\text { y fomento al trabajo } \\
\text { en equipo... }\end{array}$ \\
\hline
\end{tabular}

La tercera y última actividad, por tanto la más complicada, fue "El Construye-todo", que consistió en un taller de construcción, de lo que ellos y ellas desearan, con materiales de desecho. Esta actividad es prácticamente libre, ya que tienen que construir lo que ellos quieran con el material proporcionado.
Los materiales fueron retales de cartulinas y de goma eva, bricks de leche, palos de helado, limpiapipas, tapones de diferentes tamaños, colores y formas, corchos, moldes de magdalenas, pegamento, silicona, lápices, bolígrafos, etc. La duración aproximada de esta actividad fue de 60 minutos.

El objetivo de esta actividad fue resolver situaciones no habituales, favorecer la creatividad y fomentar el reciclaje de materiales de la vida cotidiana. Además, desarrollar la psicomotricidad fina, gestionar sus emociones 0 tomar decisiones.

Para la realización de la actividad, la organización espacial y de agrupamientos fue a través de talleres, que es una organización del trabajo infantil, donde se realizan actividades puntuales con el fin de enseñarles a los niños y niñas algo nuevo, en este caso a utilizar los materiales que solemos tirar para convertirlo en un objeto nuevo (Borghi, 2005). Además, en esta forma de organización, las actividades son más sistematizadas y dirigidas por el maestro/a, que en los rincones. Aunque en mi caso les dejé totalmente libertad para levantarse y coger el material y construyeran lo que quisieran.

\begin{tabular}{|c|c|}
\hline Título actividad & $\begin{array}{l}\text { "El Construye- } \\
\text { todo" }\end{array}$ \\
\hline $\begin{array}{l}\text { Materiales } \\
\text { utilizados }\end{array}$ & $\begin{array}{ll}\text { Material } & \text { de } \\
\text { desecho } & \\
\text { Retales } & \text { de } \\
\text { cartulinas } & \\
\text { Retales de } & \text { goma } \\
\text { eva } & \\
\text { Limpiapipas } & \\
\text { Pegamento } & \end{array}$ \\
\hline
\end{tabular}




\begin{tabular}{|l|l|}
\hline & $\begin{array}{l}\text { Bolígrafos } \\
\text { Silicona }\end{array}$ \\
\hline Duración & $60^{\prime}$ \\
\hline Objetivo & $\begin{array}{l}\text { Resolver } \\
\text { situaciones no } \\
\text { habituales. }\end{array}$ \\
\hline
\end{tabular}

\section{RESULTADOS}

Para comenzar con los resultados, primero explicar que los he narrado a modo de diario de clase, que es donde el docente toma notas de lo que ocurre en clase, anécdotas y momentos importantes en el aula.

Además quiero exponer el porqué de la elección de las actividades explicadas anteriormente, ya que algunas fueron posterior a mi visita al colegio y a las observaciones que obtuve.

Antes de comenzar a realizar actividades de mi investigación basada en las artes, estuve en momentos puntuales de la jornada escolar en el aula donde las iba a realizar para ver qué tipo de actividades no estaban acostumbrados a hacer y así provocarles un conflicto. Observé el trabajo de la maestra, las actividades que hacían, el comportamiento que tenían los niños y niñas y sobre todo la motivación y si les resultaba fácil o no realizar las actividades que suelen hacer.

En el aula se trabaja poco la creatividad, puesto que su principal finalidad es acabar las fichas programadas para llevar el libro acabado cuando finalice el trimestre. En cuanto a la educación plástica, utilizaron plastilina y dibujaron un paisaje (determinado por la maestra). En cuanto a la educación musical, no realizaron ninguna actividad fuera de lo que es cantar y recitar de memoria las canciones de buenos días y las que avisan de que los rituales en el aula cambian. En cuanto a la educación física, salen fuera del aula para dar dos sesiones de psicomotricidad a la semana, de 45 minutos cada una.

De este modo decidí que estas actividades podrían motivarle ante el conflicto progresivo con el que se encuentran $y$, además, ver cómo reaccionan ante actividades inusuales, al menos en el aula.

La actividad 1: "Miniyó" la propuse porque consideré que era una actividad que no les iba a suponer ningún tipo de problemas, ya que la plastilina es un material que en las aulas de infantil está a la orden del día.

Una vez en el aula, les expliqué lo que íbamos a hacer y repartí los 7 colores de plastilina en los cuatro rincones que había en clase y comencé a observar...

Todos los niños y niñas eligieron un trozo de plastilina de un color y yo me preguntaba: ¿Por qué solo utilizan un color teniendo siete diferentes? y sus respuestas fueron diversas:

N1 -Niño/a 1-: "Los muñecos de "plasti" solo son de un color".

N2: "Porque es mi color favorito".

N3: "Porque no me han dejado más colores".

N4: "Solo me gusta coger un color".

Curiosamente, la maestra únicamente ofrecía al alumnado la plastilina de un solo color, a objeto de evitar que la 
mezclasen entre ellas y no pudieran ser reutilizadas tras formarse la "plasti marrón" a la que algunos y algunas maestros y maestras le temen tanto. Esta elección cohibía la creatividad de los niños y niñas, pues impedían que mezclaran y jugasen con total libertad con dicho material.

Pero, ¿no es importante que los niños y niñas manipulen? ¿Por qué no mezclar plastilinas para experimentar los cambios de color?

Todo el alumnado tenía su trozo de plastilina elegido, pero ¿por qué no modelan si ya tienen todo lo que les hace falte? Ante esta pregunta la N1 (una niña muy participativa) preguntó: "¿Pero es que no nos vas a dar folios para no manchar la mesa de "plasti"?".

Ante esta situación, decidí hablar con ellos para explicarles que con esta plastilina que había llevado, no pasaba nada si la mezclaban, que podían utilizar la que quisieran y de los colores que quisieran y que hoy no íbamos a utilizar folios para no manchar la mesa, que íbamos a probar a limpiar con un trapo cuando terminásemos.

Ahora sí, comenzaron a modelar. Algunos se mostraron desubicados porque no eran lo que estaban acostumbrados a hacer, no sabían por dónde empezar. Otros se decidieron probar a mezclar colores y volvieron las preguntas:

N5: "Pero seño, ¿Cómo nos vamos a hacer a nosotros con plastilina?".

N6: "Seño, yo esto no se hacerlo".
N7: "Pues es como una vez que hicimos un muñeco, ¿no os acordáis? Solo que tenemos que ponerle nuestro pelo $y$ nuestra ropa".

N8: "Yo no sé hacerlo, ¿me ayudas?".

N9: “Seño, ¿así está bien?”.

En este momento fue cuando me di cuenta que la actividad que yo pensaba que deberían de realizar con total facilidad, iba a ser la que más resultados de la investigación podría obtener.

Continuaron modelando, reclamando $\mathrm{mi}$ ayuda, y sobre todo, mi aprobación. Necesitan constantemente que el docente les diga que está bien hecho o mal hecho. ¿Acaso yo puedo "corregir" cómo se ve un niño o niña? ¿Puedo decidir sobre los colores que usa?

Considero que la necesidad de constante aprobación se debe a que hoy día, en muchos colegios (más de los que deberían) los niños y niñas son educados en la realización de actividades que no son significativas para ellos y con un resultado preestablecido. No se escuchan las razones que los niños y niñas pueden dar en cuanto al resultado "erróneo" de alguna de esas actividades, por tanto ellos hacen lo que deben hacer y esperan a que su actividad sea como la de todos, sin un ápice de creatividad para así llevarse un tic verde o una carita sonriente a casa.

La mayoría del alumnado comienza a terminar la creación de su "Miniyó", así que me paso a escuchar su explicación. En este momento, N10 (muy tímido) me reclama casi lloroso porque no consigue hacer su miniyó y necesita mi ayuda para terminarlo a tiempo. 
¿La educación artística y estética contribuye al desarrollo de la inteligencia emocional? Un caso.

https://dx.doi.org/10.17561/rtc.n16.4

Continuamos con las exposiciones de sus miniyós y éstas son algunas de sus creaciones y explicaciones:

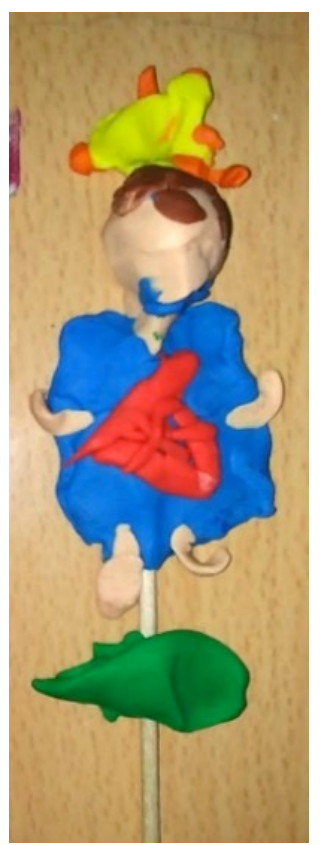

"Este soy yo con un balón rojo porque me encanta jugar al fútbol en el campo".

La plastilina amarilla representa el sol, la roja un balón, la verde el césped.

Este niño se ha representado como se ve: pelo marrón y piel clarita con la ropa que llevaba (azul) y haciendo lo que más le gusta: jugando al fútbol en el parque del pueblo.

Fig. 1: Miniyó $n^{\circ} 2$

“¿Ves los rizos? ¡Son como los míos! Y tengo mi ropa favorite".

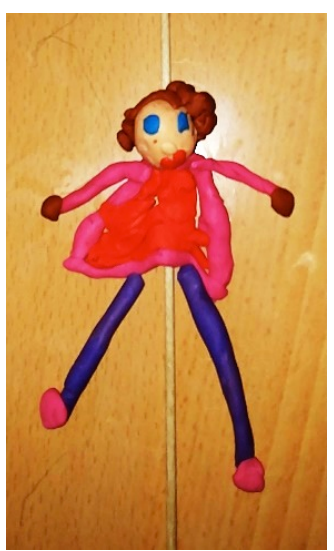

En este caso, se ha representado con los rasgos que más la caracterizan: pelo rizado y ojos azules. Además se ha hecho la ropa del bautizo de su hermano: un vestido rosa y rojo y unos zapatos rosas.

Fig.3: Miniyó $n^{\circ} 7$

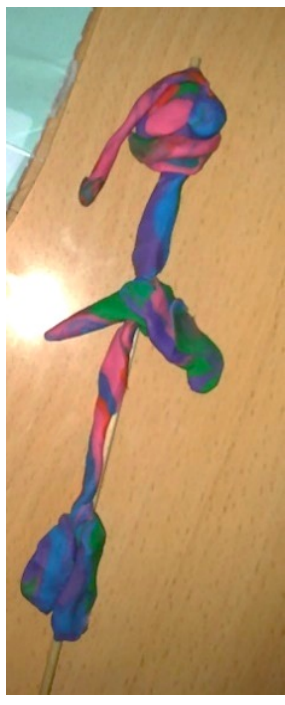

"Mis colores favoritos son el rosa, el azul, el morado y el verde y soy yo con el pelo largo, mis ojos y mis brazos".

Esta niña se ha representado un poco más abstracta, utilizando y mezclando sus colores favoritos. No se ha parado en detallar la ropa que tenía o colores predeterminados que todos tenemos, por

Fig. 2: Miniyó ejemplo el color de la $n^{\circ} 12$ piel. Se representa tal y como se ve en el espejo: con su pelo largo, sus ojos, su boca, su cuerpo y sus extremidades.

"Mira que guapo he quedado con mi pelo

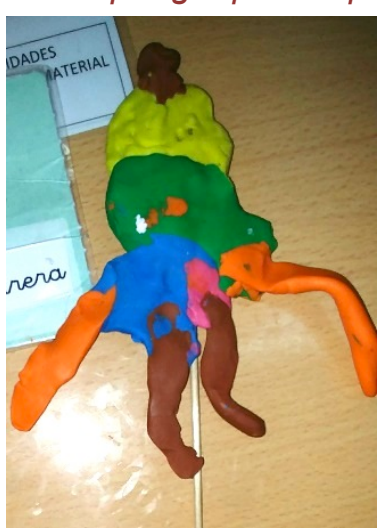
rubio".

Se ha representado su pelo rubio de punta, pero en versión monstruo, porque según él es "tan malo como un monstruo".

Fig. 4: Miniyó n¹8 
ISSN: 2340-9096

https://dx.doi.org/10.17561/rtc.

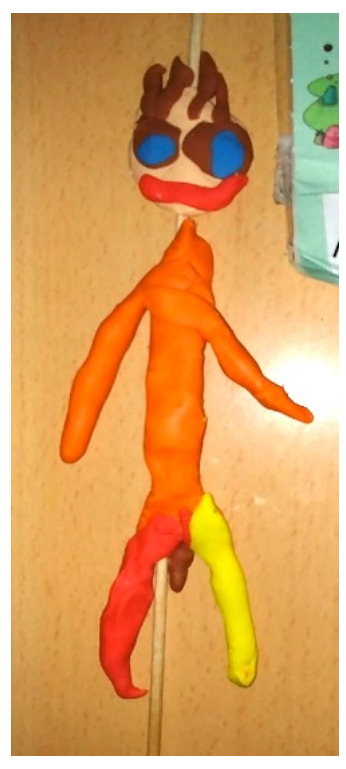

Fig. 5: Miniyó n¹4 que ha representado su genital.

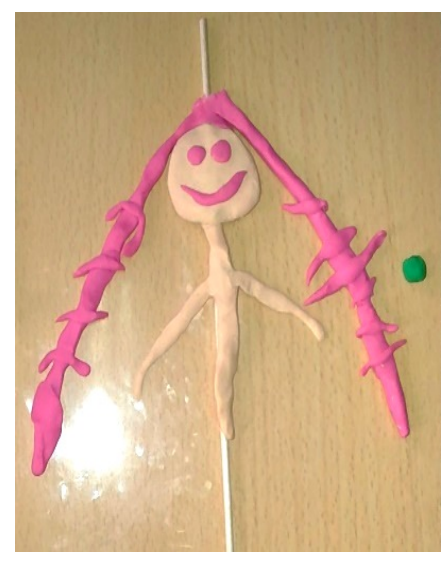

Esta niña se ha representado con algo que le caracteriza y es su piel blanquita. Además, ha elegido pelo rosa y largo porque no le gusta su pelo naranja y corto.

Fig. 6: Miniyó $n^{\circ 1}$

"Me he hecho con carne porque soy muy blanquita, el pelo rosa porque me encanta y las rayitas son trenzas, porque estoy muy guapa con ellas".

En cuanto a las figuras expuestas anteriormente, he escogido estas porque considero que fueron las más sorprendentes: la Figura 5 se representó con sus órganos genitales, la Figura 6 cómo le gustaría tener el pelo, la Figura 2 y 4 modificando su imagen real, etc.

Además se puede ver cómo cada uno de los niños y niñas se han representado con algo característico suyo, mostrando así un conocimiento y expresión de sí mismo y de sus intereses. Como por ejemplo, en la Figura 1 se representa jugando al fútbol y en la Figura 3, con sus rizos y ojos azules, sus rasgos más característicos.

En la mayoría de los casos, se han representado siendo fieles a sí mismos, es decir, con la cabeza redonda, color de su piel, cuerpo, extremidades, etc., excepto en el caso de la Figura 2 y 4 que son los que más han cambiado su forma real.

La actividad 2: "Cuéntame un cuento", se eligió puesto que en lo poco que había observado, la creación literaria es una práctica que los niños y niñas de esta etapa no están habituados a realizar.

Considero que en la Educación Infantil, éste tipo de creación es una fuente muy importante para desarrollar la imaginación y la creatividad, además de motivar a los niños y niñas. También se promueve la lectura, ya que con cada cuento que inventemos se pueden hacer los dibujos, se escriben los diálogos, se 
encuaderna y pasa a formar parte de nuestra biblioteca de aula, motivándolos y haciendo que sientan la necesidad de llevarse los cuentos a casa para compartirlos con sus familias.

Esta actividad la realicé 6 días después y en cuanto me vieron los niños y niñas empezaron a preguntarme:

N16: "¿Qué vamos a hacer hoy?" N1: "¿Hoy también vamos a hacer cosas chulas?"

N23: “¿Quién eres? ¡Yo no quiero hacer nada! ¡Me duele la barriga!"

Posteriormente, ya sentados en la asamblea, expliqué que íbamos a inventarnos un cuento, que íbamos a proponer ideas y se elegiría la que más le gustase a la mayoría y que todo lo que fuésemos decidiendo lo íbamos a ir escribiendo y dibujando en una pizarra.

Para comenzar la creación del cuento, estaban muy desconcertados. Esto demostraba que para ellos era una actividad totalmente nueva, que nunca habían llevado a cabo, por eso la mayoría recurrió a cuentos clásicos como "Los 3 cerditos", "Peter Pan" o "Blancanieves" para hacer sus propias creaciones.

Por tanto, empecé a guiarlos sobre cómo querían que empezara el cuento, qué fórmula utilizarían, etc. A continuación elegimos los personajes, en el que las niñas querían príncipes y princesas y los niños payasos asesinos; al igual que el lugar en el que transcurriría la historia, ya que en el caso de las niñas preferían situar la narración dentro de un castillo y en el caso de los niños, el campo. Una elección estereotipada que llama considerablemente la atención, pues demuestra de alguna manera esa desigualdad que todavía arraiga en la educación actual y que, según algunos estudios, podría conllevar a ataduras y restricciones de género a muy temprana edad, lo que podría tener graves consecuencias en sus vidas (García, 2017).

Ante la poca imaginación, les digo que tiene que ser un cuento divertido que tenemos que elegir personajes que cuando los escuches juntos te de risa y no sea un cuento más de príncipes y princesas. Además, tenemos un diálogo sobre el porqué quieren que el payaso sea asesino, cuando la función principal del payaso, en principio, sería hacernos reír. Sus respuestas llamaron mucho la atención:

N19: "Los payasos si son asesinos, porque lo he visto en el móvil de mi mama".

N1: "Bueno pero a lo mejor son solo algunos".

N6: "Yo nunca he visto un payaso malo".

N22: "Yo también he visto payasos asesinos en el móvil de mi papá".

N10: "Entonces los de los circos son buenos y los del móvil son malos".

¿Por qué los niños y niñas de 5 años tienen acceso a los móviles de los padres? ¿Por qué los niños y niñas una vez que tienen acceso a las tecnologías no tienen supervisión de lo que ven o dejan de ver? Hoy en día, la mayoría de padres y madres para que los niños y niñas no les molesten en sus tareas, les dan el móvil o la tablet sin ningún tipo de supervisión. De esta forma pueden 
acceder a contenidos nada apropiados para su edad y conseguir que piensen que tanto lo que consumen por la televisión como por internet sea una verdad absoluta. Considero también que esto es un factor influyente, en mayor o menor medida, ante el problema de la poca creatividad que hay en los colegios.

Volviendo a la creación del cuento, hicimos lluvia de ideas sobre qué personajes, ahora sí preferían. Las propuestas fueron toros, conejos, payasos, brujas, hadas, caballos, etc. Dado que fueron muchas las propuestas, sometimos a votación cada uno de los personajes y nos quedábamos con los tres o cuatro que tenían más votos.

Cuando les expliqué qué íbamos a votar, no sabían qué había que hacer. Por tanto les expliqué que había que levantar la mano cuando se dijera el personaje que más le gustaba y que en cada personaje íbamos a contar las manos que había levantadas. Tras dicho recuento, pasaríamos a ver qué personajes tenían más votos. En este caso, fue una bruja, un delfín, un hada y un payaso.

Para la elección del espacio donde se narra el cuento y para los hechos más importantes del mismo, utilizamos la misma técnica de voto. Si a alguien no le gustaba lo que algún compañero o compañera decía, podía hacer una propuesta nueva y así someterla a votación (solo cuando había varias propuestas).

El espacio del cuento se concretó en el castillo de la bruja y en el campo, donde había un lago para el delfín. El tiempo que se acordó fue de día, una mañana después de desayunar.

A medida que íbamos avanzando en la invención del cuento me iba dando cuenta que lo que más les gustaba era votar. Constantemente decían que no les gustaba lo que había dicho su compañero o compañera, pero cuando le decía: "Bueno, a ver dime un trozo tú por si les gusta más". Las repuestas, sobre todo del N24 eran: "No, yo no digo nada, yo sólo quiero votar, jvamos a votar!"

Cuando ya teníamos todas las partes del cuento, le narré lo que entre todos habíamos acordado por si querían cambiar algo. Pero, N1 dijo: "Al cuento le falta lo más guay: el nombre".

Comenzamos a pensar títulos de cuentos y algunos volvieron a ponerle Peter Pan, Los tres cerditos o Blancanieves. Ante esto, otros reaccionaron:

N1: "Pero en nuestro cuento no aparece Peter Pan, ni cerditos".

N18: "Es que me gusta Peter Pan y quiero ponerle Peter Pan".

N1: "Pues no puede ser, vamos a decir más y votamos".

Volvimos a decir nombres para el cuento, pero ahora sí, intentando inventárnoslo y que tuviera algo que ver con nuestro cuento.

Algunos de los títulos más votados fueron: El castillo, La bruja, el payaso y el hada, Buscando al payaso o Polvos mágicos. 
¿La educación artística y estética contribuye al desarrollo de la inteligencia emocional? Un caso.

https://dx.doi.org/10.17561/rtc.n16.4

Y, ahora sí, así quedó el cuento:

\section{POLVOS MÁGICOS}

Había una vez una bruja llamada Peliloca que vivía en un castillo. La bruja tenía un delfín como mascota y juntos fueron a dar un paseo.

En ese paseo, se encontraron con el hada Brillos y les dijo: ¿Puedo ir con vosotros? Estoy un poco aburrida y no sé qué hacer.

Peliloca contestó: ¡Claro! Vamos a buscar a mi amigo el payaso Mucharisa y verás que bien lo vamos a pasar.

El hada, la bruja y el delfín comenzaron a buscar a Mucharisa, pero no lo encontraban por ningún lado...

Lo buscaron en el lago y no estaba. Lo buscaron en el campo, debajo de las piedras, detrás de los arbustos y encima de los árboles. Pero tampoco estaba.

Así que fueron a buscarlo al castillo de la bruja Peliloca. El hada Brillos lo buscó dentro de los cajones y no estaba.

Peliloca lo buscó en la cocina y no estaba...

De repente escucharon desde la

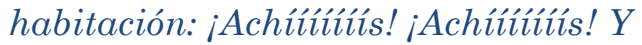
todos fueron corriendo... Y alli estaba Mucharisa, metido debajo de la cama.

Mucharisa le preguntó: ¿Pero qué haces ahí? ¡Hemos estado buscándote toda la tarde! A lo que Mucharisa contestó: ¡No te lo vas a creer, en el castillo hay hadas! Mira, he descubierto sus polvos mágicos.

De repente el delfín, la bruja Peliloca y el hada Brillos comenzaron a reír y le dijeron: ;Sal de debajo de la cama y verás!

Cuando el payaso Mucharisa vio a Brillos se sorprendió y dijo:

¿Pe...pe...pero tú eres un hada? ¿Es tuyo este polvo mágico? ¿Qué puedo hacer con él?

El hada le explicó: Es mi polvo mágico, con él puedo hacer invisible a las personas o incluso meter una cocina debajo de la cama. Toma, te regalo un poquito para que lo puedas utilizar cuando tú quieras.

Yasí, el payaso Mucharisa, la bruja Peliloca y el hada Brillos pasaron una divertida tarde con los polvos mágicos.

Colorín colorado... jeste cuento se ha acabado!

Para concluir con las actividades, después de una semana de la realización de la actividad 2, realicé la actividad 3 : "El construye-todo".

Esta actividad estaba decidida antes de ir al colegio, porque es una actividad que he realizado en otros centros y considero que les ayudaría a ver las cosas más allá de lo que son. Una vez que presencié las actividades que solían hacer, ratificó mi decisión de realizarla.

Las dos actividades anteriores las realicé en el aula habitual, ya que las actividades fueron a través de rincones y en la asamblea. Como expliqué en el apartado 
anterior, ésta fue a través de un taller, por lo que nos trasladamos a la sala del aula matinal del colegio.

Esta clase está puesta con mesas largas, donde caben todos los niños y niñas, facilitando la observación y supervisión del trabajo. Una vez situados, les explico que nos vamos a convertir en constructores y que, con diferentes objetos que a continuación les mostré, íbamos a hacer un objeto nuevo.

Además les dejé que se agruparan como quisieran, pero en ese grupo debían de construir una cosa consensuada entre todos los miembros y todos debían participar en la elaboración.

El G1 -Grupo 1- estaba compuesto por niños y niñas, y todos eran de carácter "mandón". El G2 lo formaban 4 niños, amigos donde uno era el líder y los demás acataban. El G3 eran 5 niñas y un niño, el niño iba por libre y no hacía caso al resto de miembros del grupo. El G4 era el más grande y mixto también, donde dos niños eran decididos y el resto esperaban mi ayuda.

Una vez presentados los materiales, los puse en el centro del aula para que tuvieran que moverse en el espacio. Tenían total libertad para coger todo lo que quisieran, eso sí, que lo utilizaran porque si no volvía al centro.

Cuando los niños y niñas vieron los materiales, se abalanzaron sobre ellos y fueron a coger absolutamente todo lo que pudieran, como si la actividad fuera: gana quien más material tenga.

Cuando ya todos los grupos tenían material, me fui pasando por los grupos para ver qué habían decidido. Tenían mucho material pero no sabían qué hacer aún.

G1: "Todavía no sabemos qué vamos a hacer, porque los chicos quieren un campo de fútbol y nosotras queremos muñecas".

G2: "Nosotros queremos hacer un animal".

G3: "Seño, no sabemos hacer nada".

G4: "Queremos hacer un robot, pero no me hacen caso".

Tanto al G1 como al G4 les dije que se tenían que poner de acuerdo, que tenían que hablar y acordar algo y en los dos grupos la contestación fue: "Vamos a votar". Al G3 les guie buscando parecidos entre el material y objetos reales. Al G2, me limité a observar.

Siguieron intentando ponerse de acuerdo, pero al final tanto en el G1, G3 y G4 hubo niños y niñas que comenzaron a construir de forma individual. Otros miembros del grupo se limitaban a observar lo que sus compañeros $y$ compañeras hacían, pero ellos no hacían nada. Estaban totalmente desubicados.

Los que fueron terminando su construcción, decidieron ayudar a los compañeros y compañeras que aún no habían hecho nada. Por tanto, hicieron todo el trabajo, ya que reprodujeron lo que habían hecho anteriormente.

Cuando acabó el tiempo que nos había dado la seño, les comuniqué que ya teníamos que volver a clase y que lo que habíamos construido se tenía que quedar así (por mi hubiéramos tenido otra sesión en la que a todos los niños y niñas les 
¿La educación artística y estética contribuye al desarrollo de la inteligencia emocional? Un caso.

https://dx.doi.org/10.17561/rtc.n16.4

hubiera dado tiempo de construir algo, ya que es una actividad a la que no están acostumbrados y todos no resuelven los problemas tan rápidamente).

Hicimos una breve exposición de los objetos realizados $y$ algunos fueron estos:

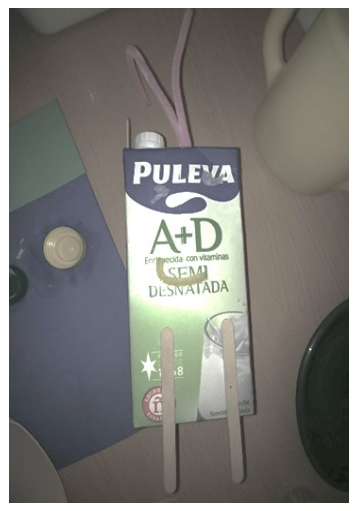

Fig. 7. Conejito feliz.

"Es un conejito feliz, porque es mi animal favorito. Con palos le he hecho las piernas y con esto (limpiapipas), la boca $y$ las orejas".

En la figura 7 aparece una construcción de un conejo con un brick de leche. Para hacerle las patas, utilizó palos de helado y para la cola y las orejas limpiapipas de su color favorito.

Este conejo fue elaborado de forma individual de N9 después de mostrar mucha inseguridad y miedo a no saber hacerlo.

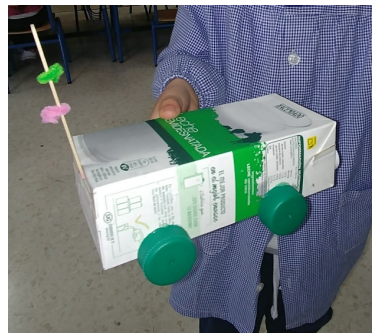

Fig. 8. Coche.

"Es el coche de mi padre".

La figura 8 es un coche elaborado con un brick de leche. Para las ruedas le ha puesto 4 ruedas verdes (compañeras al brick de leche) y la antena de la radio la realizó con un palo de helado y adornándolo con trozos de limpiapipas.

Este conejo fue elaboración de forma individual de $\mathrm{N} 14$, en este caso fue el primer objeto que se realizó, el niño decidió qué hacer y lo ejecutó sin preguntar ni dudar.

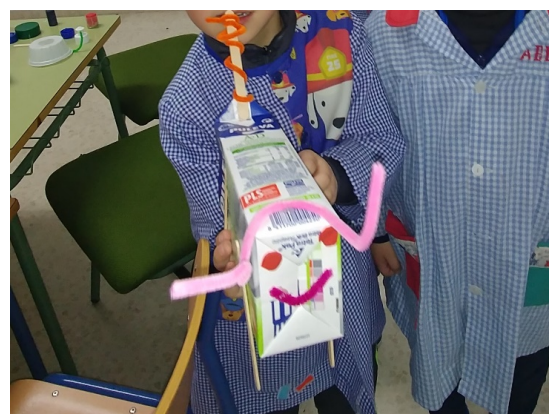

Fig. 9.

Torito

bravo.

La figura 9 es un toro realizado con un brick de leche para el cuerpo, palos de helado para las patas y la cola, limpiapipas para la boca, los cuernos y para adornar la cola y plastilina para los ojos.

Este toro fue elaboración del G2, donde un niño fue el inventor y casi por completo el constructor. 
Revista de Estudios en Sociedad, Artes y Gestión Cultural

Número 16

Julio 2019
ISSN: $2340-9096$

https://dx.doi.org/10.17561/rtc. http://revistaselectronicas. ujaen.es/index.php/RTC

www.terciocreciente.com

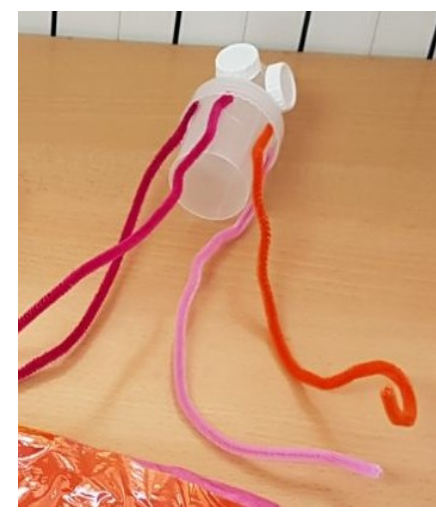

Fig.10.

Medusa.

"Esta

medusa es

para mi

hermanito

porque es

su favorito".

En la figura

9 se ve una

medusa

elaborada con un tapón de suavizante de las lavadoras, con dos tapones de leche y limpiapipas simulando los tentáculos.

Fue elaboración individual de N1 después intentar a hacer una muñeca y no obtener un resultado que le gustase.

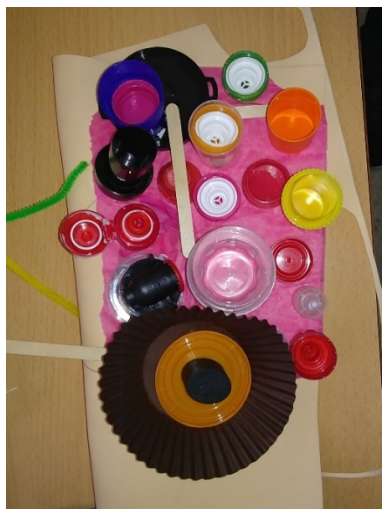

Fig. 11. Máquina de inventos.

"Es una máquina que inventa cosas con muchos botones para cambiar el color, la forma y todo".

En la figura 11 aparece, una máquina que inventa cosas realizada con tapones de diferentes colores y tamaños sobre goma eva y papel pinocho.
Este objeto fue construido por N25, un niño que no suele participar excesivamente en las actividades grupales, pero que ha demostrado gran creatividad en esta actividad.

Por tanto, los niños y niñas que hicieron algo que estaba acabado, lo presentaron a sus compañeros y compañeras. De esta forma, a los que no pudieron resolver el conflicto que se propuso se sintieron frustrados e incluso una niña comenzó a llorar y decía que no se iba a la otra clase si no le ayudaba a hacer algo.

Para concluir y poner punto y final a la realización de actividades quería escuchar lo que sintieron, qué les gustó más y qué menos y qué ha sido lo más difícil.

En general, la actividad que más gustó fue la 1: "Miniyó" y la que menos la actividad 2: "Cuéntame un cuento". La primera práctica, creo que fue más fácil para ellos y es donde ellos se sintieron más cómodos. La segunda, por el contrario, creo que fue la más aburrida para ellos porque no vieron un producto final a su realización y por ello la que menos les gustó. La actividad 3: "EI construye-todo", ha sido considerada la más difícil porque es a la que menos están acostumbrados a hacer y la que provocó un mayor conflicto cognitivo en ellos. 


\section{CONCLUSIONES}

Después de haber explicado los resultados obtenidos en la investigación basada en las artes para dar respuesta a la pregunta que da título a este trabajo: ¿La educación artística y estética contribuye al desarrollo de la inteligencia emocional?, he llegado a una serie de conclusiones.

Trabajando la educación estética y artística se desarrollan múltiples aspectos de la inteligencia emocional como la resolución de conflictos, colaboración, participación, confianza, motivación, emociones, respeto, creatividad, autonomía, etc.

En muchos colegios, pero en concreto el que ha sido objeto de mi estudio, opta por una educación más conceptual y tradicional. Por tanto se educa a los niños y niñas a que conozcan cosas y no se tiene muy en cuenta los procedimientos que hacen que lleguen a un concepto y la actitud ante éste.

Por tanto, el arte es una disciplina que no está muy integrada en nuestro sistema educativo y cuando se hace, no creo que sea la mejor forma de tratarlo.

Y a partir de aquí, todo está encadenado. Si no se trabaja el arte (en cualquier disciplina), no se trabaja la educación estética ni la artística. Si esto no se trabaja, tampoco se desarrolla la creatividad y la imaginación, siendo éstas lo más apreciado que tienen los niños y niñas de estas edades. Si no son creativos e imaginativos, ¿qué les queda? ¿Repasar el número 5 con una línea? ¿Esperar la aprobación de la maestra o maestro?

A través de las actividades realizadas el alumnado ha puesto de manifiesto aspectos que no suelen poner en práctica en el aula, como la frustración que les ha supuesto el no saber qué hacer producido por la libertad de dichas propuestas, el estrés por no acabar "a tiempo las actividades", el no tomar decisiones ante ningún tipo de situación, etc.

Son niños y niñas que no están motivados porque saben lo que les espera uno y otro día (y no saben que les queda toda una vida entre esas cuatro paredes), no tienen autonomía porque están acostumbrados a que tienen que hacer lo que dice la seño y cómo ella lo dice, no saben canalizar sus sentimientos (sobre todo la frustración), no saben trabajar en grupo ya que la educación que tienen es más bien individualista, no tienen un autoestima alto ya que tienen miedo al fracaso y necesitan la constante aprobación de que lo que está haciendo está bien, etc.

Lo más impactante es que tienen una necesidad a que les escuchen, a que tengan en cuenta su opinión, sus gustos y lo que tienen que decir (que es muy valioso). En el momento que se les escucha, como en el caso de las votaciones de la actividad "Cuéntame un cuento", se sienten importantes y por tanto su autoestima aumenta.

Por todo lo observado me hago la pregunta: ¿es necesario trabajar la inteligencia emocional en el aula? Considero que es lo primordial en la 
ISSN: $2340-9096$

https://dx.doi.org/10.17561/rtc.
http://revistaselectronicas.ujaen.es/index.php/RTC educación. Primero hay que partir del propio individuo, conocerse, saber reaccionar ante problemas y situaciones, ser autónomo...para posteriormente conocer el entorno a través de los diferentes lenguajes, tal y como viene establecido en nuestro currículo. La inteligencia emocional, es la base del resto de las inteligencias, por tanto hay que trabajar la base para subir a la cima.
Para concluir, quiero hacerlo con una cita del actor norteamericano David Caruso que añade "es muy importante entender que la inteligencia emocional no es lo opuesto a la inteligencia, no es el triunfo del corazón sobre la cabeza, es la intersección de ambas" 
¿La educación artística y estética contribuye al desarrollo de la inteligencia emocional? Un caso. https://dx.doi.org/10.17561/rtc.n16.4

\section{Referencias}

Bonilla Marquínez, Olga Patricia y Gómez Betancourt, Mauricio (2015). "El valor de la fotografía como expresión de la inteligencia emocional”. En Revista Académica e Institucional Páginas de la UCP, No 98: p.79-95.

Borghi, Battista Quinto (2005). Los talleres en educación infantil: espacios de crecimiento (Vol. 12). Barcelona: Graó.

Caíña, Euclides Padilla (2008). La educación estética postmoderna. Revista Espiga, 8(16), p. 189-216.

Cueva Ramírez. María Lorena. (2017). ¿Por qué es importante seguir luchando por la Educación Artística? Tercio Creciente, 11, págs. 151-160. DOI: 10.17561/rtc.n11.10

Dewey, John. (2008). El arte como experiencia. Barcelona: Paidós.

D'Angelo, Estella y Medina, Ángeles. (1997). La asamblea en educación infantil: su relación con el aprendizaje y con la construcción de la autonomía. Revista Investigación en la Escuela, (33), p. 79-88.

Escamilla, Amparo (2014). Inteligencias múltiples. Claves propuestas para su desarrollo en el aula. Barcelona: Graó

Escamilla, Amparo (2014). Inteligencias múltiples. Coordenadas para una colaboración efectiva familia-centro. Padres y Maestros/Journal of Parents and Teachers, (360), p. 23-27.

García, Carolina (2017). “Los estereotipos de género se arraigan en los niños y niñas a los 10 años". El País. Disponible en: 


\section{https://elpais.com/elpais/2017/09/26/mamas papas/1506419592 704218.html}

(Consultado el 4 de abril de 2018).

Gardner, Howard. (1998). Inteligencias múltiples. Barcelona: Paidós.

Gardner, Howard. (2012). La inteligencia reformulada. Las inteligencias múltiples del siglo XXI. Barcelona: Paidós.

Goleman, Daniel (1995). Emotional intelligence: Why it can matter more than IQ for character, health and lifelong achievement. Editorial Kairós.

Goleman, Daniel (2012). Inteligencia emocional. Editorial Kairós.

Guillén, Jesús (2015). "Neuromitos en el aula: de las inteligencias múltiples al Brain Gym”. Escuela con cerebro. Disponible en:

https://escuelaconcerebro.wordpress.com/2015/05/17/neuromitos-en-el-aula-de-lasinteligencias-multiples-al-brain-gym/ (Consultado el 25 de mayo de 2018).

Hernández, Fernando (2008). La investigación basada en las artes. Propuestas para repensar la investigación en educación. Educatio siglo XXI, 26, p. 85-118.

Laguía, María José y Vidal, María José (2007). Rincones de actividad en la Escuela Infantil (0 a 6 años). Barcelona: Graó.

Mairal, Jorge Barraca (2011). Estética y formación humana: el valor de estética en la educación. Educación y Futuro: Revista de investigación aplicada y experiencias educativas, (24), p. 205-219.

Palomera Martín, Raquel., y Yépez De Domicis, Adriana. (2016). Educación responsable. Un programa para fomentar el desarrollo emocional, social y de la 
¿La educación artística y estética contribuye al desarrollo de la inteligencia emocional? Un caso. https://dx.doi.org/10.17561/rtc.n16.4

creatividad en toda la comunidad educativa. Padres y Maestros/Journal of Parents and Teachers, (368), p. 24-29.

Sánchez, Galo (2010). Educación estética y educación artística. Reflexiones para una enseñanza creativa. Aula, 16, p. 21-32.

Soto Sánchez, Pilar (2017). "Las diosas del huerto. El dibujo como investigación artística y meditación". Afluir, 1, págs. 10-21

http://accionsocialyarte.com/index.php/publicaciones/revista-afluir

Ubals Álvarez, José Manuel (2005). Educación estética y educación artística: un diálogo no agotado desde la infinitud cercana. 